\title{
Intake of the First-Generation Anti-Histamines in Early Childhood May Have an AdverseEffecton Cognitive Function. Population BasedPharmacoepidemiologic Study in Non-Asthamtic Children
}

\author{
Wieslaw A Jedrychowski*, Elżbieta Flak', Elzbieta Mroz ${ }^{1}$, Maria Butscher ${ }^{2}$ and Agata Sowa ${ }^{1}$ \\ ${ }^{1}$ Chair of Epidemiology and Preventive Medicine, Jagiellonian University Medical College in Krakow, Poland \\ ${ }^{2}$ Polish-American Institute of Pediatrics, Jagiellonian University Medical College in Krakow, Poland
}

\begin{abstract}
As the allergic diseases increase steadily worldwide, the main goal of the study was to assess the association between the early intake of the first-generation sedative antihistamines in young non-asthmatic children and their cognitive function at the age of 7 . The size of the exposure effect was measured by the Wechsler intelligence Scale for Children (WISC-R) and adjusted in multivariable models for major confounders known to be important for children cognitive development. The study included 212 children who were non-asthmatic and completed the monitoring of antihistamines intake over 3 years preceding the WISC-R intelligence testing.
\end{abstract}

While the first-generation drugs were used by $36.7 \%$ children and the newer generation by $39.6 \%$, both categories of drugs were taken by $17.8 \%$ children. The analysis showed the deficit of 12 points on the verbal WISC-R IQ scale only in children who used the first- generation antihistamines for a longer time (beta coeff. $=-11.7,95 \% \mathrm{Cl}$ : $-19.6,-3.7)$ compared to non-users. Out of the covariates included in the multivariable regression models, maternal education (beta coeff. $=0.92,95 \% \mathrm{Cl}: 0.37,1.46$ ) and breastfeeding at least for 6 months (beta coeff. $=3.29 ; 95 \% \mathrm{Cl}$ : $0.34,6.23$ ) showed a significant positive impact on the verbal IQ. Intake of the newer generation antihistamines were associated neither with verbal nor performance IQ scores.

Concluding, the results suggest that the "sedative antihistamines" have a negative impact on the verbal but not performance IQs of young children if drugs were used over a longer period. The weaker verbal communication ability of young children may hinder the cognitive development of children and be associated with relatively poor school academic achievements.

Keywords: Epidemiologic study; Children; Antihistamines; Cognitive function

\section{Introduction}

Drugs with antihistamine action are among the commonly prescribed medicines in pediatrics for the symptomatic treatment of various allergic disorders such as, seasonal and perennial allergic rhinitis, conjunctivitis, atopic dermatitis or chronic urticaria. Antihistamines presently available on the market have been classified as first, second or third generation drugs and they differ in the chemical structures, pharmacodynamics, pharmacokinetics and adverse health events [1-5]. First-generation antihistamines used traditionally (diphenhydramine, chlorpheniiramine, clemastine, hydroxyzine, triprolidine and promethazine) are highly lipid soluble, have a low molecular weight and a high affinity for cerebral $\mathrm{H} 1$ receptors. They easily cross the blood brain barrier and show highly sedating effect on central nervous system even at low therapeutic doses. Sedation reflects the impairment of cognitive functions such as attention, memory, language, coordination or psychomotor performance, which can hinder daily activities, where mental concentration and skill are required [6-11]. As children are more sensitive to the side-effects of drugs than adults, the side effects may have implications for their further long-term intellectual development.

The newer generation antihistamines (astemizole, terfenamide, loratanide, cetirizine, fexofenadine) known as "nonsedative antihistamines", like the first-generation antihistamines have a similar affinity for the $\mathrm{H} 1$ receptor. However, having greater molecular weight they do not easily cross the blood brain barrier and do not cause unwanted CNS side effects. Hence, most newer-generation antihistamines have a much more favourable therapeutic index [12-16].
Most of the studies to assess the sedative effect of the $\mathrm{H} 1$ antagonists were carried out in the groups of asthmatic children. Although asthma is not a disease that directly affects cognitive development, but the effect of the disease may delay a child's cognitive development since children in severe asthma attacks may not receive adequate care in an optimal way and experience anoxic episodes. Subsequently, a child experiencing many anoxic insults may suffer from a cognitive delay due to the insufficient supply of oxygen to the brain [17].

The main purpose of this prospective epidemiologic population based study was to establish whether an early use of the first-generation antihistamines by young non-asthmatic children could have affected their cognitive function measured at the age of 7. The size of the effect on the cognitive scores was measured by the Wechsler Intelligence Scale for Children (WISC-R) and adjusted for major confounders known to be important for children cognitive development such as, maternal

${ }^{*}$ Corresponding author: Wieslaw Jedrychowski, Department of Epidemiology and Preventive Medicine, Jagiellonian University Medical College, 7, Kopernika Street, Krakow, Poland, Tel: +48-12-423-1003; Fax: +48-12-422-8795; E-mail: myjdryc@cyf.krakow.pl

Received April 25, 2013; Accepted July 27, 2013; Published July 29, 2013

Citation: Jedrychowski WA, Flak E, Mroz E, Butscher M, Sowa A (2013) Intake of the First-Generation Anti-Histamines in Early Childhood May Have an Adverse Effect on Cognitive Function. Population Based Pharmacoepidemiologic Study in Non-Asthamtic Children. Adv Pharmacoepidemiol Drug Saf 2: 138. doi:10.4172/2167-1052.1000138

Copyright: (c) 2013 Jedrychowski WA, et al. This is an open-access article distributed under the terms of the Creative Commons Attribution License, which permits unrestricted use, distribution, and reproduction in any medium, provided the original author and source are credited. 
education, the child's gender, breastfeeding practice, the presence of older siblings, and environmental tobacco smoke (ETS).

\section{Material and Methods}

This is part of an ongoing comparative longitudinal investigation on the health impact of prenatal exposure to outdoor/indoor air pollution in infants and children being conducted in Krakow, Poland. As described previously [18], between January 2001 and February 2004, we recruited a total of 484 womens between 8 and 13 weeks pregnant, who had born term babies ( $>36$ weeks of gestation) and were registered at prenatal healthcare clinics in the central area of Krakow, where they had also lived for at least a year before screening. Pregnant women visiting the prenatal clinic received a letter of introduction and answered a short screening questionnaire to determine whether they met the eligibility criteria-age $\geq 18$ years, non-smoking, singleton pregnancy, no current occupational exposure to known developmental toxicants and no history of illicit drug use, pregnancy-related diabetes, or hypertension. All participants received verbal and written information about the study. Ethical permission for the study was granted by the Bio-ethical Committee of Jagiellonian University Medical College.

The present study included 212 term babies who were nonasthmatic and completed the monitoring of intake of antihistamine drugs over 3 years preceding the WISC-R intelligence testing at the age 7 . Estimated daily intake of oral antihistamines by children over the 3 -years period preceding WISC-R testing were based on regular face-to-face interviews performed every 6 months by the trained field workers with mothers. Name(s) of the drug(s) reported by mothers had to be supported by showing the interviewer original packagings or containers of the drug(s) used. Detailed data on maternal education was used as a proxy for social class, intellectual ability and quality of parenting. Mothers were also asked whether the infant had ever been breastfed, and, if so, the age of the baby (in months) when exclusive breastfeeding was stopped. Exclusive breastfeeding was assumed if the child received only breast milk, and no other liquids or solids with the exception of medicine, or mineral supplements. Mixed feeding was assumed when the child received both breast milk and formula or only formula since birth. As maternal intelligence is a known correlate of child cognitive development, we administered the Test of Nonverbal Intelligence (TONI-3) to the mothers at the 4th year of follow-up. Data on the presence of tobacco smoking household members was used to define environmental tobacco smoke (ETS) at home.

\section{Mental development testing of children}

At age 7 , the WISC-R was used, which is the most widely used intelligence and neuropsychological assessment and is considered to be a valid and reliable measure of general intelligence in children $[19,20]$. It has also been found to be a good measure of both inductive and deductive reasoning but it also measures knowledge and skills primarily influenced by biological and socio-cultural factors. The WISC-R includes questions of general knowledge, traditional arithmetic problems, vocabulary, completion of mazes, and arrangements of blocks and pictures and yields three IQ (intelligence quotient) scores, based on an average of 100, as well as subtests and index scores. WISC-R subtests measure specific verbal and performance abilities. The child's verbal IQ score (VIQ) is derived from scores on six of the subtests: information, digit span, vocabulary, arithmetic, comprehension, and similarities. The information subtest is a test of general knowledge, including questions about geography and literature. The digit span subtest requires the child to repeat strings of digits recited by the examiner. The vocabulary and arithmetic subtests are general measures of the child's vocabulary and arithmetic skills. The comprehension subtest asks the child to solve practical problems and explain the meaning of simple proverbs. The similarities subtest asks the child to describe the similarities between pairs of items, for example that apples and oranges are both fruits. The child's performance IQ score (PIQ), which is a measure of non-verbal intellectual abilities is derived from scores on the seven subtests: picture completion, picture arrangement, block design, object assembly, coding, mazes, and symbol search. In the picture completion subtest, the child is asked to complete pictures with missing elements. The picture arrangement subtest entails arranging pictures in order to tell a story. The block design subtest requires the child to use blocks to make specific designs. The object assembly subtest asks the child to put together pieces in such a way as to construct an entire object. In the coding subtest, the child makes pairs from a series of shapes or numbers. The mazes subtest asks the child to solve maze puzzles of increasing difficulty. The symbol search subtest requires the child to match symbols that appear in different groups. Scores on the performance subtests are based on both the speed of response and the number of correct answers. The Wechsler scales were standardized for Polish children and are meant to be representative of the Polish population. The practical standardization of these tests was done during team practice sessions with Ms. Maria Butscher, a psychologist from the Jagiellonian University Medical College, who subsequently evaluated the IQ scoring.

\section{Statistical data analysis}

In the descriptive analysis, the distribution of various parameters related to the women and newborns under study were presented. Chisquare statistics (nominal variables) and analysis of variance (numerical variables) tested differences between subgroups included in the study and that who did not fully participate in the monitoring of the drug intake. The relationship between IQ scores of children and the exposure to antihistamines was evaluated by linear multivariable regression models. The models computed regression coefficients of the dependent variable (intelligence IQ scores) on the main predictor variable (antihistamines) accounting for potential confounders or modifiers (gender of child, maternal education, parity, breastfeeding practice and ETS). As the correlation coefficients between cognitive scores achieved by children and maternal education (number of schooling years) and maternal IQ assessed by TONI test did not differ, we have chosen to consider only maternal education as a proxy for maternal intellectual ability and quality of parental care. All statistical analyses were performed with STATA 12.1 version software for Windows.

\section{Results}

General characteristics of the study were presented in Table 1. As the characteristics of the subjects included in the analysis did not reveal significant differences compared with the group of children who dropped out of the study, except for the children's gender, we may assume that the material included in the analysis was representative of the population sample recruited initially (Table 2).

Overall mean VIQ scores in the study population was a little lower (mean $=119.8 ; 95 \%$ CI: 118.4-121.3) than that for PIQ scores (mean $=124.6$; 95\% CI: 122.9-126.3), but the difference was statistically insignificant. Out of the whole study sample, 56\% children took antihistamines of various generations over shorter or longer period. The first-generation drugs were used by $36.7 \%$ children and the newer generation drugs by $39.6 \%$ children; both categories of drugs were taken by $17.8 \%$ children. The average use of the first generation drugs 
Citation: Jedrychowski WA, Flak E, Mroz E, Butscher M, Sowa A (2013) Intake of the First-Generation Anti-Histamines in Early Childhood May Have an Adverse Effect on Cognitive Function. Population Based Pharmacoepidemiologic Study in Non-Asthamtic Children. Adv Pharmacoepidemiol Drug Saf 2: 138. doi:10.4172/2167-1052.1000138

\begin{tabular}{|c|c|c|c|c|c|}
\hline \multicolumn{2}{|l|}{ Variables } & \multirow{3}{*}{$\begin{array}{c}\begin{array}{c}\text { Total } \\
\mathbf{N}=\mathbf{2 2 5}\end{array} \\
27.83\end{array}$} & \multicolumn{2}{|c|}{$\begin{array}{c}\text { Use of antihistamine } \\
\text { drugs }\end{array}$} & \multirow{2}{*}{$\begin{array}{c}\begin{array}{c}\text { P for } \\
\text { difference }\end{array} \\
\end{array}$} \\
\hline & & & $(-) \mathrm{N}=147$ & (+) N=78 & \\
\hline \multirow[t]{2}{*}{ Maternal age: } & mean & & 28.24 & 27.06 & \multirow[t]{2}{*}{0.0157} \\
\hline & SD & 3.481 & 3.415 & 3.495 & \\
\hline \multirow{2}{*}{$\begin{array}{l}\text { Maternal education: } \\
\text { (years of schooling) }\end{array}$} & mean & 15.80 & 15.90 & 15.62 & \multirow[t]{2}{*}{0.4580} \\
\hline & SD & 2.711 & 2.754 & 2.635 & \\
\hline \multirow{2}{*}{$\begin{array}{ll}\text { Parity: } & 1 \\
& \geq 2\end{array}$} & $n(\%)$ & $146(64.9)$ & 91 (61.9) & $55(70.5)$ & \multirow[t]{2}{*}{0.2540} \\
\hline & $n(\%)$ & 79 (35.1) & $56(38.1)$ & $23(29.5)$ & \\
\hline \multirow{2}{*}{$\begin{aligned} \text { Gender: Boys } \\
\text { Girls }\end{aligned}$} & $\mathrm{n}(\%)$ & $104(46.2)$ & 64 (43.5) & $40(51.3)$ & \multirow[t]{2}{*}{0.3328} \\
\hline & $n(\%)$ & $121(53.8)$ & $83(56.5)$ & $38(48.7)$ & \\
\hline \multirow{2}{*}{$\begin{array}{l}\text { Gestational age: } \\
\text { (weeks) }>36\end{array}$} & mean & 39.44 & 39.49 & 39.36 & \multirow[t]{2}{*}{0.3975} \\
\hline & SD & 1.101 & 1.043 & 1.206 & \\
\hline \multirow[t]{2}{*}{ Birth weight (g): } & mean & 3424.7 & 3438.8 & 3398.1 & \multirow[t]{2}{*}{0.5033} \\
\hline & SD & 432.89 & 438.67 & 423.29 & \\
\hline \multirow[t]{2}{*}{ Length at birth $(\mathrm{cm})$ : } & mean & 54.82 & 54.93 & 54.60 & \multirow[t]{2}{*}{0.3690} \\
\hline & SD & 2.611 & 2.691 & 2.457 & \\
\hline \multirow{2}{*}{$\begin{array}{l}\text { Head circumference } \\
(\mathrm{cm}) \text { : }\end{array}$} & mean & 33.90 & 33.94 & 33.83 & \multirow[t]{2}{*}{0.5972} \\
\hline & SD & 1.420 & 1.406 & 1.454 & \\
\hline $\begin{array}{l}\text { Breastfeeding } \\
\text { exclusive }>6 \text { months }\end{array}$ & $n(\%)$ & $62(27.6)$ & $45(30.6)$ & $17(21.8)$ & 0.2106 \\
\hline \multirow{2}{*}{$\begin{array}{l}\text { Postnatal ETS } \\
\text { (1-7 age) }\end{array}$} & $n(\%)$ & $32(14.4)$ & $22(15.2)$ & $10(13.0)$ & \multirow[t]{2}{*}{0.8099} \\
\hline & $\begin{array}{l}\text { Missing } \\
\text { date }\end{array}$ & 3 & 2 & 1 & \\
\hline
\end{tabular}

Table 1: Characteristics of the study sample and the intake of the first-generation antihistamines by non asthmatic children.

\begin{tabular}{|c|c|c|c|c|c|}
\hline Variables & & \multirow{2}{*}{$\begin{array}{c}\begin{array}{c}\text { Total } \\
\mathbf{N}=484\end{array} \\
27.55\end{array}$} & \multirow{2}{*}{$\begin{array}{c}\begin{array}{c}\text { Monitoring } \\
\mathbf{N}=\mathbf{2 2 5}\end{array} \\
27.83\end{array}$} & \multirow{2}{*}{$\begin{array}{c}\begin{array}{c}\text { Monitoring } \\
\text { was not } \\
\text { completed } \\
\mathbf{N}=259\end{array} \\
27.31\end{array}$} & \multirow{2}{*}{\begin{tabular}{|c}
$\begin{array}{c}\text { P for } \\
\text { difference }\end{array}$ \\
0.1069 \\
\end{tabular}} \\
\hline Maternal age: & mean & & & & \\
\hline & SD & 3.580 & 3.481 & 3.653 & \\
\hline \multirow{2}{*}{$\begin{array}{l}\text { Maternal education: } \\
\text { (years of schooling) }\end{array}$} & mean & 15.56 & 15.80 & 15.36 & \multirow[t]{2}{*}{0.0795} \\
\hline & $\mathrm{SD}$ & 2.759 & 2.711 & 2.790 & \\
\hline \multirow{2}{*}{ Parity: $\begin{array}{r}1 \\
\geq 2\end{array}$} & $\mathrm{n}(\%)$ & $307(63.4)$ & $146(64.9)$ & $161(62.2)$ & \multirow[t]{2}{*}{0.5985} \\
\hline & $\mathrm{n}(\%)$ & $177(36.6)$ & $79(35.1)$ & $98(3$ & \\
\hline \multirow{2}{*}{$\begin{array}{r}\text { Gender: Boys } \\
\text { Girls }\end{array}$} & $\mathrm{n}(\%)$ & $248(51.2)$ & $104(46.2)$ & $144(55.6)$ & \multirow[t]{2}{*}{0.0492} \\
\hline & $\mathrm{n}(\%)$ & $236(48.8)$ & $121(53.8)$ & $115(44.4)$ & \\
\hline \multirow{2}{*}{$\begin{array}{l}\text { Gestational age: } \\
\text { (weeks)>36 }\end{array}$} & mean & 39.54 & 39.44 & 39.62 & \multirow[t]{2}{*}{0.0955} \\
\hline & $\mathrm{SD}$ & 1.141 & 1.101 & 1.170 & \\
\hline \multirow[t]{2}{*}{ Birth weight $(\mathrm{g})$ : } & mean & 3443.0 & 3424.7 & 3459.0 & \multirow[t]{2}{*}{0.3880} \\
\hline & $\mathrm{SD}$ & 435.90 & 432.89 & 438.71 & \\
\hline \multirow[t]{2}{*}{ Length at birth $(\mathrm{cm})$ : } & mean & 54.75 & 54.82 & 54.69 & \multirow[t]{2}{*}{0.5956} \\
\hline & SD & 2.615 & 2.611 & 2.622 & \\
\hline \multirow{2}{*}{$\begin{array}{l}\text { Head circumference } \\
\text { (cm): }\end{array}$} & mean & 33.91 & 33.90 & 33.91 & \multirow[t]{2}{*}{0.9437} \\
\hline & $\mathrm{SD}$ & 1.391 & 1.420 & 1.368 & \\
\hline $\begin{array}{l}\text { Breastfeeding } \\
\text { exclusive }>6 \text { months }\end{array}$ & $\mathrm{n}(\%)$ & $133(27.5)$ & $62(27.6)$ & $71(27.4)$ & 1.0000 \\
\hline
\end{tabular}

Table 2: Characteristics of the children who completed the drug monitoring and those who failed to complete it.

was 9 days (95\% CI: 8.9-9.7 days), and the newer generation drugs were used much longer i.e., 48 or more days (95\% CI: 46.8-48.6).

While there was a significant negative trend of the verbal IQ scores with the use of the first-generation antihistamines, no such pattern was noticed in children who used the second or third generation drugs (Table 3). The distribution of verbal IQ scores was markedly shifted to lower values in the group of children who were longer exposed to antihistamines of the first- generation (Figure 1).

In order to assess the adjusted impact of the first-generation antihistamines on IQ WISC-R scales, multivariable linear regression models were used, where a set of potential confounding variables (maternal education, gender of child, parity, breastfeeding practice, ETS, and co-exposure to the newer generation drugs) were included (Tables 4-6). The significant deficit of 12 points on the verbal IQ scale attributable to the first- generation antihistamines was noticed if used longer (beta coeff. $=-11.7,95 \%$ CI: $-19.6,-3.7$ ) (Table 4). Out of the confounders inserted in the regression models, maternal education (beta coeff. $=0.92,95 \%$ CI: $0.37,1.46$ ) and breastfeeding for 6 months or longer (beta coeff. $=3.29 ; 95 \%$ CI: $0.34,6.23$ ) showed a significant positive impact on cognitive function.

Table 5 and 6 show that the negative effects of the first-generation antihistamines on the performance and full Wechsler IQ scales were insignificant and the beneficial impact of education and breastfeeding

\begin{tabular}{|c|c|c|c|c|c|}
\hline \multirow[t]{2}{*}{ IQ scores } & \multicolumn{4}{|c|}{ Intake of the first generation drugs* } & \multirow{2}{*}{$\begin{array}{l}\text { Nonparame- } \\
\text { tric test for } \\
\text { trend }\end{array}$} \\
\hline & $\begin{array}{c}\text { No-users } \\
\text { exposure } \\
\mathrm{N}=173\end{array}$ & $\begin{array}{c}\text { Short } \\
\text { intake } \\
\mathrm{N}=35\end{array}$ & $\begin{array}{c}\text { Moderate } \\
\text { intake } \\
\mathrm{N}=9\end{array}$ & $\begin{array}{c}\text { Long } \\
\text { intake } \\
\mathrm{N}=7\end{array}$ & \\
\hline $\begin{array}{l}\text { IQ verbal } \\
\text { scale }\end{array}$ & $\begin{array}{c}120.6 \\
119.0-122.1\end{array}$ & $\begin{array}{c}120.9 \\
116.8-124.9\end{array}$ & $\begin{array}{c}118.1 \\
111.2-125.0\end{array}$ & $\begin{array}{c}110.9 \\
104.2-117.5\end{array}$ & $\begin{array}{l}Z=-2.21 \\
P=0.027\end{array}$ \\
\hline $\begin{array}{l}\text { IQ non- } \\
\text { verbal scale }\end{array}$ & $\begin{array}{c}124.2 \\
122.3-126.2\end{array}$ & $\begin{array}{c}125.7 \\
121.4-130.0\end{array}$ & $\begin{array}{c}124.8 \\
114.4-135.1\end{array}$ & $\begin{array}{c}125.9 \\
110.7-140.9\end{array}$ & $\begin{array}{c}Z=0.62 \\
0.538\end{array}$ \\
\hline $\begin{array}{l}\text { IQ full } \\
\text { scale }\end{array}$ & $\begin{array}{c}124.7 \\
123.1-126.4\end{array}$ & $\begin{array}{c}125.7 \\
121.8-129.6\end{array}$ & \begin{tabular}{|c|}
123.4 \\
$114.7-132.2$
\end{tabular} & $\begin{array}{c}122.6 \\
113.3-131.9\end{array}$ & \\
\hline \multirow[t]{2}{*}{ IQ scores } & \multicolumn{4}{|c|}{$\begin{array}{l}\text { Intake of the second and/or third generation } \\
\text { drugs }{ }^{* *}\end{array}$} & \multirow{2}{*}{$\begin{array}{l}\text { Nonparame- } \\
\text { tric test for } \\
\text { trend }\end{array}$} \\
\hline & $\begin{array}{c}\text { No-users } \\
\text { exposure } \\
\mathrm{N}=136\end{array}$ & \begin{tabular}{|}
$\begin{array}{r}\text { Short } \\
\text { intake } \\
\mathrm{N}=44\end{array}$ \\
\end{tabular} & $\begin{array}{c}\text { Moderate } \\
\text { intake } \\
\mathrm{N}=32\end{array}$ & $\begin{array}{c}\text { Long } \\
\text { intake } \\
\mathrm{N}=13\end{array}$ & \\
\hline $\begin{array}{l}\text { IQ verbal } \\
\text { scale }\end{array}$ & $\begin{array}{c}120.7 \\
118.9-122.5\end{array}$ & $\begin{array}{c}118.1 \\
114.2-122.0\end{array}$ & $\begin{array}{c}119.7 \\
118.1-123,3\end{array}$ & $\begin{array}{c}116.2 \\
105.6-126.8\end{array}$ & $\begin{array}{l}Z=-0.51 \\
P=0.611\end{array}$ \\
\hline $\begin{array}{l}\text { IQ non- } \\
\text { verbal scale }\end{array}$ & $\begin{array}{c}124.5 \\
122.4-126.6\end{array}$ & $\begin{array}{c}124.2 \\
120.0-128.3\end{array}$ & $\begin{array}{c}125.6 \\
121.1-130.1\end{array}$ & $\begin{array}{c}126.0 \\
116.0-136.0\end{array}$ & $\begin{array}{l}Z=0.23 \\
P=0.818\end{array}$ \\
\hline IQ full scale & $\begin{array}{c}124.9 \\
123.1-126.6\end{array}$ & $\begin{array}{c}123.2 \\
119.3-127.0\end{array}$ & $\begin{array}{c}125.0 \\
121.9-128.1\end{array}$ & $\begin{array}{c}125.4 \\
117.4-133.3\end{array}$ & $\begin{array}{l}Z=0.21 \\
P=0.832\end{array}$ \\
\hline
\end{tabular}

Intake of the first generation drugs ${ }^{*}$

Short-term intake: 8-28 days (mean 15 days)

Moderate-term intake: $28-42$ days (mean 35 days)

Long-term intake: 43-140 (mean 74 days)

Intake of the second and/or third generation drugs**

Short-term intake: $<189$ days (mean 53 days)

Moderate-term intake: 190-364 days (mean 285 days)

Long-term intake: $>364$ days (mean 728 days)

Table 3: Trends for cognitive function of children at age 7 and the intake of the antihistamine drugs over three years preceding IQ testing.

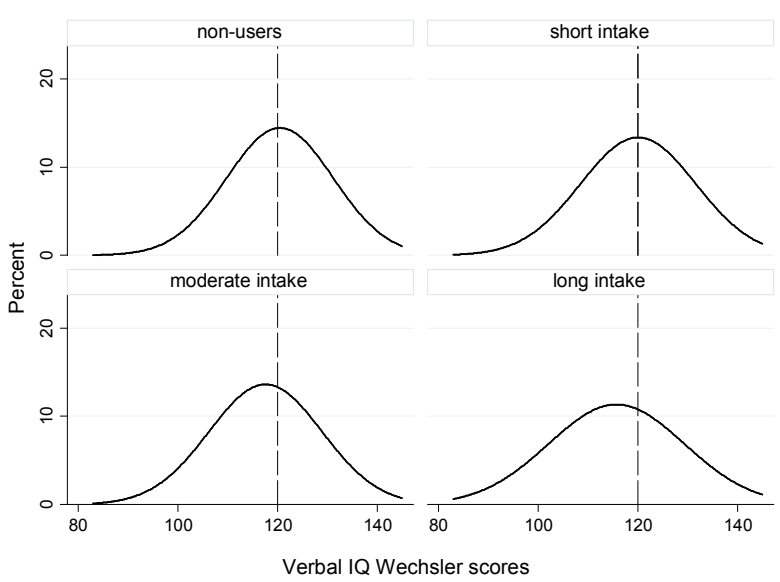

Figure 1: Distribution patterns of WISC-R scores and the intake of the first generation antihistamines (dash line: mean score in non-users). 
Citation: Jedrychowski WA, Flak E, Mroz E, Butscher M, Sowa A (2013) Intake of the First-Generation Anti-Histamines in Early Childhood May Have an Adverse Effect on Cognitive Function. Population Based Pharmacoepidemiologic Study in Non-Asthamtic Children. Adv Pharmacoepidemiol Drug Saf 2: 138. doi:10.4172/2167-1052.1000138

\begin{tabular}{|l|c|c|c|c|c|}
\hline Predictors & Coef. & T & P>t & [95\% Conf. & Interval] \\
\hline Gender of child (girls) & -1.73 & -1.25 & 0.213 & -4.48 & 1.06 \\
\hline Maternal education & 0.92 & 3.34 & 0.001 & .376 & 1.46 \\
\hline $\begin{array}{l}\text { Parity (numer of older } \\
\text { siblings) }\end{array}$ & -1.99 & -1.78 & 0.077 & -4.19 & 0.22 \\
\hline Exclusive breastfeeding & 3.29 & 2.20 & 0.029 & 0.34 & 6.23 \\
\hline $\begin{array}{l}\text { Postnatal exposure to } \\
\text { ETS }\end{array}$ & -2.39 & -1.09 & 0.277 & -6.73 & 1.94 \\
\hline Intake of antihistamines (1st generation) & & & & \\
\hline 1. Short intake & 1.242 & 0.64 & 0.525 & -2.60 & 5.08 \\
\hline 2. Moderate intake & -4.25 & -1.21 & 0.227 & -11.16 & 2.67 \\
\hline 3. Long intake & -11.65 & -2.89 & 0.004 & -19.60 & -3.69 \\
\hline Intake of antihistamines (2 & or $3^{\text {rd }}$ generation) \\
\hline 1. Short intake & -0.65 & -0.35 & 0.723 & -4.27 & 2.97 \\
\hline 2. Moderate intake & -0.73 & -0.35 & 0.724 & -4.78 & 3.33 \\
\hline 3. Long intake & 0.17 & 0.05 & 0.957 & -5.97 & 6.30 \\
\hline
\end{tabular}

Intake of the first generation drugs*

Short-term intake: 8-28 days (mean 15 days)

Moderate-term intake: $28-42$ days (mean 35 days)

Long-term intake: 43-140 (mean 74 days)

Intake of the second and/or third generation drugs**

Short-term intake: $<189$ days (mean 53 days)

Moderate-term intake: 190-364 days (mean 285 days)

Long-term intake: $>364$ days (mean 728 days)

Table 4: Association between the verbal IQ scores and the intake of the first generation anti-histamines adjusted for potential confounders. Multivariable linear regression model.

\begin{tabular}{|c|c|c|c|c|c|}
\hline Predictors & Coef. & $\mathbf{T}$ & $P>t$ & {$[95 \%$ Conf. } & Interval] \\
\hline Gender of child (girls) & 2.71 & 1.51 & 0.132 & -0.83 & 6.24 \\
\hline Maternal education & 0.31 & 0.88 & 0.381 & -0.39 & 1.01 \\
\hline $\begin{array}{l}\text { Parity (numer of older } \\
\text { siblings) }\end{array}$ & 1.97 & 1.37 & 0.173 & -0.87 & 4.81 \\
\hline Exclusive breastfeeding & 1.59 & 0.83 & 0.410 & -2.21 & 5.39 \\
\hline $\begin{array}{l}\text { Postnatal exposure to } \\
\text { ETS }\end{array}$ & -2.87 & -1.01 & 0.312 & -8.46 & 2.72 \\
\hline \multicolumn{6}{|c|}{ Intake of antihistamines ( $1^{\text {st }}$ generation) } \\
\hline 1. Short intake & 2.20 & 0.88 & 0.382 & -2.75 & 7.16 \\
\hline 2. Moderate intake & -0.17 & -0.04 & 0.970 & -9.09 & 8.74 \\
\hline 3. Long intake & 1.63 & 0.31 & 0.755 & -8.63 & 11.89 \\
\hline \multicolumn{6}{|c|}{ Intake of antihistamines ( $2^{\text {nd }}$ or $3^{\text {rd }}$ generation $)$} \\
\hline 1. Short intake & 0.09 & 0.04 & 0.970 & -4.57 & 4.75 \\
\hline 2. Moderate intake & 1.02 & 0.39 & 0.700 & -4.20 & 6.25 \\
\hline 3. Long intake & -1.48 & -0.37 & 0.713 & -9.39 & 6.43 \\
\hline
\end{tabular}

Intake of the first generation drugs ${ }^{*}$

Short-term intake: $8-28$ days (mean 15 days)

Moderate-term intake: $28-42$ days (mean 35 days)

Long-term intake: 43-140 (mean 74 days)

Intake of the second and/or third generation drugs**

Short-term intake: $<189$ days (mean 53 days)

Moderate-term intake: 190-364 days (mean 285 days)

Long-term intake: $>364$ days (mean 728 days)

Table 5: Association between the performance IQ scores and the intake of the first generation anti-histamines adjusted for potential confounders. Multivariable linear regression model.

were not seen (Table 4). As for the full IQ scale (Table 6) the positive effect of maternal education remained significant (beta coeff. 0.69; $95 \%$ CI: $0.13,1.26)$.

Figure 2 visualizes the patterns of relationship between the intake of the first and newer generation antihistamines and verbal IQ scores based on adjusted values estimated from multivariable regression models. While the exposure to the newer antihistamines did not affect verbal IQ scores, its level markedly decreased when the intake of the

first-generation drugs was reported over longer time (more than 60 days).

\section{Discussion}

Up to now the side-effects of the first-generation antihistamines on cognitive function of children have not been adequately studied. In contrast, the second-generation antihistamines have been subjected to many studies, which have provided a much better knowledge of their safety and optimal paediatric dosage in various allergic disorders. To our knowledge, this is the first pharmacoepidemiologic population based study performed in early childhood aimed at assessing the relationship between the intake of the first generation antihistamines and WISC-R test, which is the most widely used to measure intelligence of children and is considered to be a valid and reliable measure of general intelligence. The study revealed that the users of the first-generation

\begin{tabular}{|c|c|c|c|c|c|}
\hline Predictors & Coef. & $\mathbf{T}$ & $P>t$ & [95\% Conf. & Interval] \\
\hline Gender of child (girls) & 0.43 & 0.30 & 0.767 & -2.44 & 3.30 \\
\hline Maternal education & 0.69 & 2.41 & 0.017 & 0.13 & 1.26 \\
\hline $\begin{array}{l}\text { Parity (numer of older } \\
\text { siblings) }\end{array}$ & -0.12 & -0.10 & 0.921 & -2.42 & 2.19 \\
\hline Exclusive breastfeeding & 2.66 & 1.70 & 0.090 & -.418 & 5.74 \\
\hline $\begin{array}{l}\text { Postnatal exposure to } \\
\text { ETS }\end{array}$ & -2.91 & -1.26 & 0.207 & -7.44 & 1.62 \\
\hline \multicolumn{6}{|c|}{ Intake of antihistamines ( $1^{\text {st }}$ generation) } \\
\hline 1. Short intake & 1.93 & 0.95 & 0.345 & -2.09 & 5.95 \\
\hline 2. Moderate intake & -2.59 & -0.70 & 0.482 & -9.82 & 4.65 \\
\hline 3. Long intake & -5.98 & -1.42 & 0.158 & -14.30 & 2.34 \\
\hline \multicolumn{6}{|c|}{ Intake of antihistamines ( $2^{\text {nd }}$ or $3^{\text {rd }}$ generation $)$} \\
\hline 1. Short intake & -0.41 & -0.21 & 0.832 & -4.19 & 3.38 \\
\hline 2. Moderate intake & 0.26 & 0.12 & 0.903 & -3.98 & 4.50 \\
\hline 3. Long intake & -0.64 & -0.20 & 0.844 & -7.01 & 5.78 \\
\hline
\end{tabular}

Intake of the first generation drugs*

Short-term intake: 8-8 days (mean 15 days)

Moderate-term intake: $28-42$ days (mean 35 days) Long-term intake: 43-140 (mean 74 days)

Intake of the second and/or third generation drugs **

Short-term intake: $<189$ days (mean 53 days)

Moderate-term intake: 190-364 days (mean 285 days)

Long-term intake: $>364$ days (mean 728 days)

Table 6: Association between the full IQ scores and the intake of the first generation anti-histamines adjusted for potential confounders. Multivariable linear regression model.

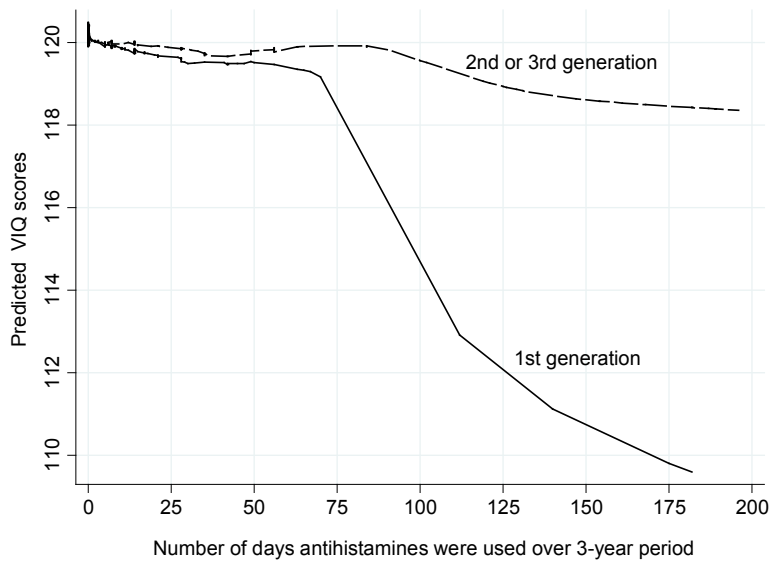

Figure 2: Predicted VIQ scores by the number of days the antihistamines were used over 3-years period. 
Citation: Jedrychowski WA, Flak E, Mroz E, Butscher M, Sowa A (2013) Intake of the First-Generation Anti-Histamines in Early Childhood May Have an Adverse Effect on Cognitive Function. Population Based Pharmacoepidemiologic Study in Non-Asthamtic Children. Adv Pharmacoepidemiol Drug Saf 2: 138. doi:10.4172/2167-1052.1000138

antihistamines had achieved a significantly lower scoring on the verbal IQ scale (beta coeff.=-11.7, 95\% CI: -19.6, -3.7) compared to non-users. All though the association between the first-generation antihistamines and the cognitive function of children was slightly attenuated in the multivariable regression model after accounting for major confounders, but the main effect remained stable and highly significant. Interestingly, the use of the first-generation drugs did not hinder the performance IQ scores.

The findings of the study are of interest as they may explain the communication problems of children and their worse potentials for academic achievements at school. Newer non-sedating secondgeneration $\mathrm{H1}$-antihistamines appeared to be free from the unwanted side-effects and detrimental effects on mental functions. In this sense, our results strongly support earlier clinical observations suggesting an impairment of learning abilities of children under treatment of the firstgeneration antihistamine drug [6,7,9-12].

At present, there is no definitive and clear explanation for the positive association between maternal education and neurocognitive development of children, which has been shown in our study. Educational level of mothers is not only a good proxy for maternal cognitive capacity and socio-economic status of the family, but it may be an indicator of other relevant factors such as maternal behavior, life style, dietary habits before and during pregnancy, all of which are important for the study of children's health. With the exception of breastfeeding, none of the above-mentioned variables were considered in our analysis. Less educated mothers are possibly not as responsive to their infants' needs as better educated mothers or they may present some less favorable behavior during early childhood. Children living in a poor socio-economic environment are more likely to be exposed to environmental hazards and the adverse effects may be more pronounced in lower compared to higher socio-economic groups.

Moreover, studies carried out by Bellinger [21] suggest that social context also modifies the effects of chemical neurotoxins. For example, material hardship has been demonstrated to modify the neurotoxic effects of tobacco smoke in children in the study done by Rauh et al. [22]. The way in which maternal behavior may affect the development of children was discussed in a recently published paper by Surkan et al. [23].

Our study confirmed a positive effect of longer exclusive breastfeeding on the verbal IQ score, which by many authors is explained by the fact that breastfed and milk-formula-fed infants could have been influenced by omega-3 polyunsaturated fatty acids that are normally present in breast milk or other bioactive components essential for development $[24,25]$. However, there are other possible mechanisms that may explain the association between breastfeeding and child cognitive function since breastfeeding may be an indicator of a safe and sound maternal attachment status, which has been shown to have a positive influence on the child's psychological development into later age [26-29]. Breastfeeding may also be a marker of other unmeasured maternal characteristics such as maternal intelligence. In our analysis, we did not consider maternal intelligence as it was found that maternal education correlated significantly with maternal cognitive capacity.

Weakness of the study results from the small size of the study sample and the lack of precise information on pediatric antihistamines doses used in early childhood. Moreover, we could not perform verification of maternal reports with medical records. However, strength of our study is the prospective design, and assessment of individual intake of antihistamine drugs by interviews with mothers at regular 6 -months intervals preceding the health outcome measurement and controlling for several major confounding covariates. In addition, a set of relevant confounders of the relationship between the intake of drugs and cognitive development such as diagnosed asthma in children, chronic diseases of mothers or maternal active tobacco smoking, have been removed through entry criteria to the study. It is important to mention as well, that the assessment of the cognitive development of children was carried out by the trained staff using the Polish version of the Wechsler-R intelligence, adapted and standardized by the Polish Psychological Society.

\section{Conclusions}

The first-generation antihistamines negatively affect verbal but not performance IQs of young children when they are used over a relatively longer time. As language development is the part of the human communication system, the weaker verbal communication function may hinder the cognitive development of children and be associated with relatively poor school academic achievements.

\section{Acknowledgements}

This is part of an ongoing comparative longitudinal investigation on the health impact of prenatal exposure to outdoor/indoor air pollution in infants and children being conducted in New York City and Krakow. In part, the study received funding from an ROI grant entitled, "Vulnerability of the Fetus/Infant to PAH, PM2.5 and ETS" (5 ROI ES10165 NIEHS; 02/01/00-01/31/04) and from the NIEHS (ROI ES010165-0451) the Lundin Foundation and the Gladys T. and Roland Harriman Foundation. Principal investigator: Prof FP Perera; Co-investigator Prof WA Jedrychowski.

\section{References}

1. Simons FE, Fraser TG, Reggin JD, Roberts JR, Simons KJ (1996) Adverse central nervous system effects of older antihistamines in children. Pediatr Allergy Immunol 7: 22-27.

2. Emanuel MB (1999) Histamine and the antiallergic antihistamines: a history of their discoveries. Clin Exp Allergy 29 Suppl 3: 1-11.

3. Brown RE, Stevens DR, Haas HL (2001) The physiology of brain histamine Prog Neurobiol 63: 637-672.

4. Simons FE (2002) H1-antihistamines in children. Clin Allergy Immunol 17: 437 464

5. Del Cuvillo A, Sastre J, Montoro J, Jauregui I, Ferrer M, et al. (2007) Use of antihistamines in pediatrics. J Investig Allergol Clin Immunol 2: 28-40.

6. Gengo F, Gabos C, Miller JK (1989) The pharmacodynamics of diphenhydramine-induced drowsiness and changes in mental performance. Clin Pharmacol Ther 45: 15-21.

7. Meltzer EO (1990) Performance effects of antihistamines. J Allergy Clin Immunol 86: 613-619.

8. Vuurman EF, van Veggel LM, Uiterwijk MM, Leutner D, O'Hanlon JF (1993) Seasonal allergic rhinitis and antihistamine effects on children's learning. Ann Allergy 71: 121-126.

9. Kay GG, Berman B, Mockoviak SH, Morris CE, Reeves D, et al. (1997) Initial and steady-state effects of diphenhydramine and loratadine on sedation, cognition, mood, and psychomotor performance. Arch Intern Med 157: 23502356.

10. Kay GG (2000) The effects of antihistamines on cognition and performance. $J$ Allergy Clin Immunol 105: S622-S627.

11. Church MK, Maurer M, Simons FE, Bindslev-Jensen C, van Cauwenberge $P$, et al. (2010) Risk of first-generation $\mathrm{H}(1)$-antihistamines: a $\mathrm{GA}(2) \mathrm{LEN}$ position paper. Allergy 65: 459-466.

12. Stevenson J, Cornah D, Evrard P, Vanderheyden V, Billard C, et al. (2002) Long-term evaluation of the impact of the h1-receptor antagonist cetirizine on the behavioral, cognitive, and psychomotor development of very young children with atopic dermatitis. Pediatr Res 52: 251-257.

13. Holgate ST, Canonica GW, Simons FE, Taglialatela M, Tharp M, et al. (2003) 
Citation: Jedrychowski WA, Flak E, Mroz E, Butscher M, Sowa A (2013) Intake of the First-Generation Anti-Histamines in Early Childhood May Have an Adverse Effect on Cognitive Function. Population Based Pharmacoepidemiologic Study in Non-Asthamtic Children. Adv Pharmacoepidemiol Drug Saf 2: 13凸 . doi:10.4172/2167-1052.100013ロ

Consensus Group on New-Generation Antihistamines (CONGA): present status and recommendations. Clin Exp Allergy 33: 1305-1324.

14. Simons FE (2004) Advances in H1-antihistamines. N Engl J Med 351: 22032217.

15. Tillement JP (2005) Pharmacologic profiles of the newer antihistamines. Clin Exp Allergy Rev 5: 7-11.

16. Banerji A, Long AA, Camargo CA Jr (2007) Diphenhydramine versus nonsedating antihistamines for acute allergic reactions: a literature review. Allergy Asthma Proc 28: 418-426.

17. Bass JL, Corwin M, Gozal D, Moore C, Nishida H, et al. (2004) The effect of chronic or intermittent hypoxia on cognition in childhood: a review of the evidence. Pediatrics 114: 805-816.

18. Jedrychowski W, Whyatt RM, Camann DE, Bawle UV, Peki K, et al. (2003) Effect of prenatal PAH exposure on birth outcomes and neurocognitive development in a cohort of newborns in Poland. Study design and preliminary ambient data. Int J Occup Med Environ Health 16: 21-29.

19. Wechsler D (1974) Manual of the Wechsler Intelligence Scale for ChildrenRevised. New York: Psychological Corporation.

20. Wechsler D (2004) Wechsler Intelligence Scale for Children-fourth edition. London, Pearson Assessment, Manual of the Wechsler Intelligence Scale for Children-Revised. New York: Psychological Corporation.
21. Bellinger DC (2008) Lead neurotoxicity and socioeconomic status: conceptual and analytical issues. Neurotoxicology 29: 828-832.

22. Rauh VA, Whyatt RM, Garfinkel R, Andrews H, Hoepner L, et al. (2004) Developmental effects of exposure to environmental tobacco smoke and maternal hardship among inner city children. Neurotoxicol Teratol 26: 373-385.

23. Surkan PJ, Schnaas L, Wright RJ, Téllez-Rojo MM, Lamadrid-Figueroa $\mathrm{H}$, et al (2008) Maternal self-esteem, exposure to lead, and child neurodevelopment. Neurotoxicology 29: 278-285.

24. Neuringer M, Connor WE (1986) n-3 fatty acids in the brain and retina: evidence for their essentiality. Nutr Rev 44: 285-294.

25. Lundqvist-Persson C, Lau G, Nordin P, Strandvik B, Sabel KG (2010) Early behaviour and development in breast-fed premature infants are influenced by omega-6 and omega-3 fatty acid status. Early Hum Dev 86: 407-412.

26. Morley R, Cole TJ, Powell R, Lucas A (1988) Mother's choice to provide breast milk and developmental outcome. Arch Dis Child 63: 1382-1385.

27. Jansen J, deWeerth C, Riksen-Walraven M (2008) Breastfeeding and the mother infant relationship: a review. Dev Rev 28: 503-521.

28. Meedya S, Fahy K, KableA(2010) Factors that positively influence breastfeeding duration to 6 months: a literature review. Women Birth 23: 135-145.

29. Whitehouse AJ, Robinson M, Li J, Oddy WH (2011) Duration of breast feeding and language ability in middle childhood. Paediatr Perinat Epidemiol 25: 44-52. 